\title{
Intra-specific diversity within Pasteurella trehalosi based on variation of capsular polysaccharide, lipopolysaccharide and outer-membrane proteins
}

\author{
R. L. Davies' and M. Quirie² \\ Author for correspondence: R. L. Davies. Tel: +441413398855 ext. 6685. Fax: +441413304600.
}

1 Division of Infection and Immunity, IBLS, Joseph Black Building, University of Glasgow, Glasgow G12 8QQ, UK

2 Moredun Research Institute, 408 Gilmerton Road, Edinburgh EH17 7JH, UK

\begin{abstract}
Intra-specific diversity within Pasteurella trehalosi was investigated by analysis of variation of capsular polysaccharide, and lipopolysaccharide (LPS) and outer-membrane protein (OMP) profiles. Sixty isolates of $P$. trehalosi, from diverse geographical locations within the UK, were examined. Capsular polysaccharide serotypes were determined by indirect haemagglutination assay; LPS and OMP profiles were compared by SDS-PAGE analysis. Capsular serotyping identified three isolates of serotype T3, 18 isolates each of serotypes T4, T10 and T15, and three untypable (UT) isolates. Analysis of LPS and OMP profiles identified six smooth LPS types and four OMP types among the 60 isolates. Forty-five $(75 \%)$ of the isolates belonged to a single OMP type whereas $52(87 \%)$ of the isolates possessed one of three LPS types. Each typing method, by itself, was not very discriminating but when the data from the three methods were combined, the 60 isolates could be separated into 14 distinct subgroups containing from one to 16 isolates as follows: serotype T3, two subgroups; serotype T4, four subgroups; serotype T10, two subgroups; serotype T15, five subgroups; UT isolates, one subgroup. Certain subgroups were associated with only one serotype whereas other subgroups were common to two or more serotypes. The subgroupings were capable of differentiating between isolates of the same serotype from the same and different geographical origins. Based on their LPS and OMP profiles, isolates of serotypes T4 and T15 were more closely related to each other than to isolates of serotype T10; serotype T4 and T15 isolates were also more heterogeneous than those of serotype T10. Certain isolates of serotype T10, recovered from a wide geographical area, were characterized by the possession of a unique capsule/LPS/OMP combination and represented a single clonal group which was responsible for a large proportion ( $31 \%$ ) of recent disease outbreaks. Overall, a combination of capsular serotyping, and LPS and OMP typing, was found to be extremely useful for assessing diversity within $P$. trehalosi and should be of value for epidemiological and virulence studies.
\end{abstract}

Keywords: Pasteurella trebalosi, diversity, capsular polysaccharide, lipopolysaccharide, outer-membrane proteins

\section{INTRODUCTION}

Pasteurella trebalosi is an important Gram-negative bacterial pathogen of sheep, being responsible primarily for a

Abbreviations: UT, untypable; OMP, outer-membrane protein; BHIB, brain heart infusion broth; NCTC, National Collection of Type Cultures; MRI, Moredun Research Institute; VI Centre, Veterinary Investigation Centre. serious systemic infection but also being associated with pneumonia (Gilmour \& Gilmour, 1989). Traditionally, $P$. trebalosi has been recognized as the $\mathrm{T}$ biotype of the socalled Pasteurella baemolytica complex, which also includes the A biotype and a number of additional groups of lesser importance and uncertain taxonomic relatedness (Gilmour \& Gilmour, 1989; Mutters et al., 1989). The A and $\mathrm{T}$ biotypes have been further subdivided into 17 
serotypes based on differences in their capsular polysaccharides (Adlam, 1989; Younan \& Fodor, 1995). Biotype $\mathrm{T}$ isolates, or $P$. trehalosi, comprise four capsular serotypes designated T3, T4, T10 and T15. The chemical structures of the serotype T4 and T15 capsular polysaccharides have been elucidated and are very similar (Adlam et al., 1985a, b). It has long been recognized that the $A$ and $T$ biotypes are responsible for distinct clinical syndromes in sheep. Biotype A is responsible for pneumonia in all ages of sheep and septicaemia in young lambs, whereas biotype $T$ is responsible primarily for a welldefined systemic disease of young adult sheep (Gilmour \& Gilmour, 1989). These pathogenic and epidemiological differences between the two biotypes were confirmed by Sneath \& Stevens (1985) who, in a numerical taxonomic study of Actinobacillus, Pasteurella and Yersinia, clearly demonstrated that the $\mathrm{A}$ and $\mathrm{T}$ biotypes were very different and suggested that they should be separate species. In a later study, Sneath \& Stevens (1990) proposed that biotype $\mathrm{T}$ of $P$. haemolytica be recognized as a new species, namely $P$. trebalosi. More recently, Dewhirst et al. (1992), using 16S rRNA sequence comparison, confirmed the findings of Sneath \& Stevens $(1985,1990)$ and demonstrated that the two species belonged to different clusters within the family Pasteurellaceae and may, in fact, belong to different genera.

Unfortunately, the $\mathrm{A}$ and $\mathrm{T}$ biotypes of $P$. baemolytica have not been widely recognized as distinct and separate species and have been treated as a single species in a number of studies since 1990 (Abdullah et al., 1990; Gerbig et al., 1992; Lacroix et al., 1993; Lee et al., 1994). The taxonomic status of the $A$ and $T$ biotypes as separate species accounts for the various differences between the two biotypes described by these authors. For example, Gerbig et al. (1992) examined the neutralizing activity of a monoclonal antibody against the leukotoxin of isolates belonging to the major $A$ and $T$ serotypes and found that the monoclonal antibody neutralized the leukotoxin produced by biotype $A$ isolates but did not neutralize the leukotoxin of biotype $T$ isolates. Similarly, Abdullah et al. (1990) and Lee et al. (1994) examined sialoglycoprotease (Gcp) activity and the presence of the $g c p$ gene among isolates belonging to each of the $A$ and $T$ biotypes and found that the $g c p$ gene and Gcp activity were present in biotype $A$ isolates but not in biotype $T$ isolates. In addition, Lacroix et al. (1993) described major differences in the LPS structure of biotype A and T isolates. All of these results are not surprising in view of the taxonomic status of the $\mathrm{A}$ and $\mathrm{T}$ biotypes as separate species and they illustrate the importance of taxonomy to other areas of bacteriological research.

Due to the fact that $P$. trebalosi has yet to gain wide acceptance as a species distinct from $P$. baemolytica, the organism has not been studied in any great detail. With the exception of a single study on DNA variation in a small sample of isolates from a restricted source, using ribotyping and restriction enzyme analysis (Jaworski et al., 1993), very little is known about genetic diversity and cell-surface variation within the species, nor about the epidemiology and virulence of, or host immunity to, the pathogen. In previous comparative and epidemiological studies, the focus has been placed primarily on capsular serotyping alone, although lipopolysaccharide (LPS) and outer-membrane protein (OMP) profiles of single, representative isolates of each serotype have occasionally been examined during the course of studies on $P$. baemolytica (Knights et al., 1990; Lacroix et al., 1993). The present study was initiated, therefore, as part of a wider investigation, using a variety of techniques, into the diversity and taxonomy of the $P$. baemolytica complex. Analysis of intra-specific variation in the capsular polysaccharide, LPS and OMPs was carried out for three reasons. (1) Basic information about these important cellsurface structures of $P$. trebalosi is lacking. (2) An analysis of the natural variation occurring in the capsular polysaccharide, LPS and OMPs of $P$. trebalosi will lead to an improvement in typing methods, which are currently based only on capsular variation, and thereby to a better understanding of the epidemiology of systemic pasteurellosis. (3) The identification of specific surface characteristics associated with disease isolates will provide a stimulus to further studies aimed at understanding the virulence mechanisms of this pathogen and host immunity against it.

\section{METHODS}

Bacterial isolates and growth conditions. Sixty isolates of $P$. trebalosi were examined in the present study, including the type strain NCTC 10370. For comparative purposes, two $P$. baemolytica isolates of serotypes A1 and A2 were also included in the study. All of the $P$. trebalosi isolates were obtained from sheep, with the exception of isolate PH604, which was obtained from a calf. Except for seven isolates obtained from the National Collection of Type Cultures (NCTC) and two isolates obtained from the Moredun Research Institute (MRI), all of the isolates were obtained from one of nine Veterinary Investigation (VI) Centres in Scotland (5), England (2) and Wales (2). The sample of isolates therefore represented widespread geographical areas within the UK. With the following exceptions, all of the isolates were derived from the lungs of different infected sheep. Five groups of three isolates were obtained from the lungs, liver and spleen, respectively, of the same infected sheep; a single isolate was obtained from the nasopharynx of a healthy sheep; and eight isolates were of unknown tissue origin. Thirty-eight isolates were obtained from sheep with systemic infection (septicaemia), eleven isolates from sheep with pneumonia, two isolates from sheep with both systemic infection and pneumonia, two isolates from apparently healthy sheep, and six isolates from sheep and one isolate from a calf of unknown disease status. Details of the isolates, including their serotype, the disease status of the host, the tissue of origin and the geographical origin, are given in Table 1.

The bacterial isolates from the MRI and from the VI Centres were submitted to Glasgow on blood agar slopes. At the VI Centres the isolates were identified as $P$. trebalosi based on clinical diagnosis, colony morphology, Gram-staining and cell morphology, and preliminary biochemical characterization. Confirmation of identity was obtained by capsular serotyping, at the MRI, as described below. Cultures from the NCTC were obtained in a freeze-dried state and reconstituted on sheep's blood agar (brain heart infusion agar containing $5 \%, v / v$, defibrinated sheep's blood). All bacterial isolates were stored at $-70^{\circ} \mathrm{C}$ in $50 \%(\mathrm{v} / \mathrm{v})$ glycerol in brain heart infusion broth 
Table 1. Details of isolates of $P$. trehalosi examined in the present study

\begin{tabular}{|c|c|c|c|c|c|c|}
\hline Isolate & $\begin{array}{l}\text { Capsular } \\
\text { serotype }\end{array}$ & $\begin{array}{l}\text { LPS } \\
\text { type }\end{array}$ & $\begin{array}{l}\text { OMP } \\
\text { type }\end{array}$ & $\begin{array}{l}\text { Disease } \\
\text { status* }\end{array}$ & $\begin{array}{c}\text { Tissue of } \\
\text { origin }\end{array}$ & VI Centre \\
\hline PH604 & T3 & $\mathbf{R}$ & 4 & $\mathrm{P}$ & Lung & Edinburgh \\
\hline NCTC 11550 & T3 & 1 & 1 & - & - & - \\
\hline PH674 & T3 & 1 & 1 & - & - & Moredun \\
\hline NCTC 10626 & $\mathrm{~T} 4$ & 3 & 1 & $\mathrm{H}$ & Nasopharynx & - \\
\hline NCTC 10627 & $\mathrm{~T} 4$ & 3 & 1 & $\mathrm{P}$ & Lung & - \\
\hline PH688 & $\mathrm{T} 4$ & 3 & 1 & $\mathrm{~S}$ & Lung & Carmarthen \\
\hline PH728 & $\mathrm{T} 4$ & 3 & 1 & $\mathrm{~S}$ & Lung & Dumfries \\
\hline PH730 & $\mathrm{T} 4$ & 3 & 1 & $\mathrm{P}$ & Lung & Dumfries \\
\hline PH738† & $\mathrm{T} 4$ & 3 & 1 & $\mathrm{~S}$ & Liver & Penrith \\
\hline $\mathrm{PH} 740 \dagger$ & $\mathrm{T} 4$ & 3 & 1 & $\mathrm{~S}$ & Lung & Penrith \\
\hline $\mathrm{PH} 742 \dagger$ & $\mathrm{T} 4$ & 3 & 1 & $\mathrm{~S}$ & Spleen & Penrith \\
\hline $\mathrm{PH} 732 \dagger$ & $\mathrm{T} 4$ & 3 & 2 & $\mathrm{~S}$ & Liver & Penrith \\
\hline $\mathrm{PH} 734 \dagger$ & $\mathrm{T} 4$ & 3 & 2 & $\mathrm{~S}$ & Lung & Penrith \\
\hline PH736† & $\mathrm{T} 4$ & 3 & 2 & $\mathrm{~S}$ & Spleen & Penrith \\
\hline $\mathrm{PH} 328$ & $\mathrm{~T} 4$ & 4 & 1 & - & - & Edinburgh \\
\hline PH716 & $\mathrm{T} 4$ & 4 & 1 & $\mathrm{~S}$ & Lung & Carmarthen \\
\hline $\mathrm{PH} 768$ & $\mathrm{~T} 4$ & 4 & 1 & $\mathrm{H}$ & Lung & Aberystwyth \\
\hline PH804 & $\mathrm{T} 4$ & 4 & 1 & $\mathrm{~S}$ & Lung & Penrith \\
\hline PH636 & $\mathrm{T} 4$ & 6 & 1 & $\mathrm{~S}$ & Lung & Edinburgh \\
\hline PH638 & $\mathrm{T} 4$ & 6 & 1 & $S$ & Lung & Edinburgh \\
\hline PH640 & $\mathrm{T} 4$ & 6 & 1 & $\mathrm{~S}$ & Liver & Edinburgh \\
\hline PH356 & T10 & 2 & 1 & - & - & Auchincruvie \\
\hline PH492 & T10 & 2 & 1 & $S$ & Lung & St Boswells \\
\hline PH504 & T10 & 2 & 1 & $\mathrm{~S}$ & Lung & St Boswells \\
\hline PH650 & T10 & 2 & 1 & $\mathrm{P}$ & Lung & Carmarthen \\
\hline PH658 & T10 & 2 & 1 & $\mathrm{P}$ & Lung & Carmarthen \\
\hline PH668 & $\mathrm{T} 10$ & 2 & 1 & $S$ & Lung & Carmarthen \\
\hline PH724 & $\mathrm{T} 10$ & 2 & 1 & $\mathrm{P}$ & Lung & Edinburgh \\
\hline PH726 & $\mathrm{T} 10$ & 2 & 1 & $\mathrm{P}$ & Lung & Dumfries \\
\hline PH746 & $\mathrm{T} 10$ & 2 & 1 & S & Liver & Penrith \\
\hline PH748 & $\mathrm{T} 10$ & 2 & 1 & $S$ & Lung & Penrith \\
\hline PH764 & $\mathrm{T} 10$ & 2 & 1 & $\mathrm{P}$ & Lung & Aberystwyth \\
\hline PH766 & T10 & 2 & 1 & $\mathrm{P}$ & Lung & Aberystwyth \\
\hline $\mathrm{PH} 798+$ & T10 & 2 & 1 & S & Lung & Penrith \\
\hline PH800t & T10 & 2 & 1 & $S$ & Liver & Penrith \\
\hline $\mathrm{PH} 802 \dagger$ & $\mathrm{T} 10$ & 2 & 1 & S & Spleen & Penrith \\
\hline NCTC 10641 & $\mathrm{~T} 10$ & 2 & 2 & - & Liver & - \\
\hline PH662 & $\mathrm{T} 10$ & 4 & 1 & $\mathrm{~S}$ & Lung & Carmarthen \\
\hline PH712 & $\mathrm{T} 10$ & 4 & 1 & $S$ & Lung & Carmarthen \\
\hline PH664 & T15 & 3 & 1 & $\mathrm{~S}$ & Lung & Carmarthen \\
\hline PH710 & T15 & 3 & 1 & S & Lung & Carmarthen \\
\hline PH718 & $\mathrm{T} 15$ & 3 & 1 & S & Lung & Carmarthen \\
\hline PH722 & $\mathrm{T} 15$ & 3 & 1 & $\mathrm{~S}$ & Lung & Carmarthen \\
\hline PH694 & T15 & 3 & 2 & $\mathrm{P} / \mathrm{S}$ & Lung & Aberdeen \\
\hline PH696 & T15 & 3 & 2 & $\mathrm{P} / \mathrm{S}$ & Lung & Aberdeen \\
\hline PH780 & $\mathrm{T} 15$ & 3 & 2 & S & Lung & Carmarthen \\
\hline NCTC 10624 & $\mathrm{~T} 15$ & 3 & 3 & - & - & - \\
\hline NCTC $10370^{T}$ & T15 & 3 & 3 & $S$ & - & - \\
\hline NCTC 10371 & $\mathrm{~T} 15$ & 3 & 3 & S & - & - \\
\hline PH744 & $\mathrm{T} 15$ & 3 & 3 & $\mathrm{~S}$ & Lung & Penrith \\
\hline PH520 & $\mathrm{T} 15$ & 4 & 1 & $\mathrm{P}$ & Lung & St Boswells \\
\hline PH676 & $\mathrm{T} 15$ & 4 & 1 & - & - & Moredun \\
\hline PH750† & $\mathrm{T} 15$ & 4 & 1 & $\mathrm{~S}$ & Lung & Penrith \\
\hline PH752† & $\mathrm{T} 15$ & 4 & 1 & $\mathrm{~S}$ & Liver & Penrith \\
\hline PH754t & $\mathrm{T} 15$ & 4 & 1 & $\mathrm{~S}$ & Spleen & Penrith \\
\hline PH648 & T15 & 5 & 1 & $\mathrm{~S}$ & Lung & Carmarthen \\
\hline PH684 & T15 & 5 & 1 & $\mathrm{p}$ & Lung & Shrewsbury \\
\hline PH792† & UT & 3 & 3 & $\mathrm{~s}$ & Lung & Penrith \\
\hline PH794 $†$ & UT & 3 & 3 & $\mathrm{~S}$ & Liver & Penrith \\
\hline PH796† & UT & 3 & 3 & $S$ & Spleen & Penrith \\
\hline
\end{tabular}

*P, pneumonia; $\mathrm{S}$, systemic infection; $\mathrm{H}$, healthy.

$\dagger$ Indicates isolates from the lung, liver and spleen of the same animal. 
(BHIB). Subsequently, bacteria were streaked onto sheep's blood agar and grown overnight at $37^{\circ} \mathrm{C}$. For preparation of outer membranes, bacteria were grown for approximately $6 \mathrm{~h}$ in $500 \mathrm{ml}$ volumes of BHIB in 2 litre Erlenmeyer flasks at $37^{\circ} \mathrm{C}$ with shaking at 120 r.p.m. To assess the effect of the stage of growth on the expression of LPS and OMPs, cultures of isolate PH328 (serotype T4 ) were grown for 4, 8, 12 and $24 \mathrm{~h}$. To assess the effect of repeated subculture on the expression of LPS and OMPs, isolate PH328 was subcultured 20 times on sheep's blood agar and outer membranes prepared after 5, 10, 15 and 20 subcultures.

Capsular serotyping. In order to identify their capsular antigen types, the isolates were serotyped by the rapid indirect haemagglutination assay, with bovine red blood cells, as described by Fraser \& Donachie (1983).

Preparation of OMPs and LPS. OMPs were obtained by Sarkosyl extraction (Filip et al., 1973) as previously described (Davies et al., 1992). LPS was obtained by proteinase K digestion (Hitchcock \& Brown, 1983) of outer membranes as previously described (Davies et al., 1992), with the exception that $\times 2$ sample buffer consisted of $0.125 \mathrm{M}$ Tris/ $\mathrm{HCl}$ ( $\mathrm{pH} \mathrm{6.8),} 20 \%$ (v/v) glycerol, $4 \%(\mathrm{w} / \mathrm{v})$ SDS, $10 \%(\mathrm{v} / \mathrm{v})$ 2-mercaptoethanol and $0.0025 \%(\mathrm{w} / \mathrm{v})$ bromophenol blue.

Protein assay. The modified Lowry procedure of Markwell et al. (1978), specific for membrane proteins, was used to standardize the protein concentrations of the outer membrane samples to $2 \cdot 0 \mathrm{mg} \mathrm{ml}^{-1}$.

SDS-PAGE. OMPs and LPS were separated by SDS-PAGE using the SDS discontinuous system of Laemmli (1970) as previously described (Davies et al., 1992). OMPs (20 $\mu \mathrm{g}$ per lane) were separated in $12 \%(\mathrm{w} / \mathrm{v})$ resolving gels; LPS $(5 \mu \mathrm{g}$ per lane) was separated in $15 \%(\mathrm{w} / \mathrm{v})$ resolving gels containing $4 \mathrm{M}$ urea. The protein molecular mass standards (Pharmacia) used were phosphorylase $b(94 \mathrm{kDa})$, bovine serum albumin $(67 \mathrm{kDa})$, ovalbumin $(43 \mathrm{kDa})$, carbonic anhydrase $(30 \mathrm{kDa})$, trypsin inhibitor $(20 \cdot 1 \mathrm{kDa})$ and $\alpha$-lactalbumin $(14.4 \mathrm{kDa})$. OMPs were visualized by staining with Coomassie Brilliant Blue and LPS by silver staining (Tsai \& Frasch, 1982).

\section{RESULTS}

\section{Serotyping}

All but three of the isolates could be assigned to one of the four recognized serotypes of $P$. trehalosi. Three isolates were of serotype T3 and there were 18 isolates each of serotypes T4, T10 and T15 (Table 1). The three isolates which could not be serotyped (PH792, PH794 and PH796) were classified as untypable (UT).

\section{SDS-PAGE analysis of LPS}

To ascertain whether any variation in LPS profiles occurred at different stages of the growth cycle or after repeated subculture, LPS was prepared from cells of the serotype T4 isolate PH328 after 4, 8, 12 and $24 \mathrm{~h}$ of growth in BHIB and after 5, 10, 15 and 20 subcultures on sheep's blood agar. The times at which bacteria were harvested corresponded to late exponential and early, middle and late stationary phases of growth, respectively. As can be seen from Fig. 1, there were no changes in the LPS profiles either at different stages of growth (lanes

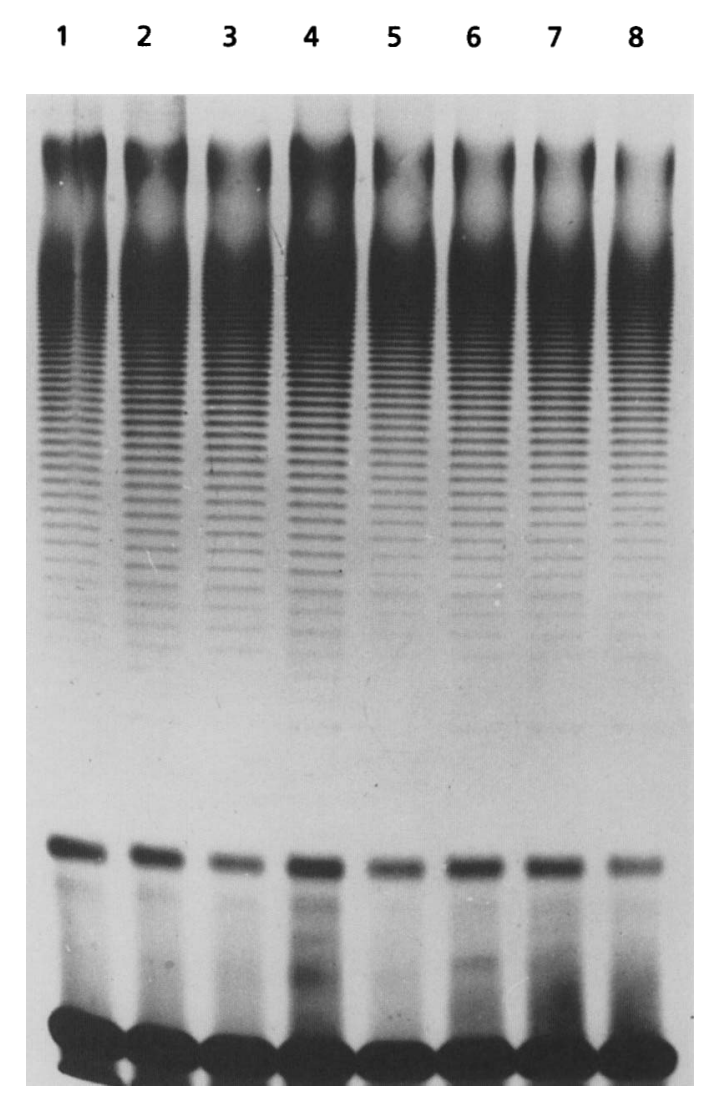

Fig. 1. LPS profiles of $P$. trehalosi isolate PH328 (serotype T4) after 4, 8, 12 and $24 \mathrm{~h}$ of growth (lanes 1-4, respectively) and after $5,10,15$ and 20 subcultures (lanes 5-8, respectively).

1-4) or after repeated subculture (lanes $5-8$ ). The LPS profile of this isolate had the characteristic ladder pattern typical of so-called 'smooth' LPS, the ladder pattern representing the additional repeat units of the O-antigen component of the molecule.

The LPS profiles of the 60 isolates of $P$. trebalosi were compared to each other and to the profiles of serotype A1 and $\mathrm{A} 2$ isolates of $P$. baemolytica. As can be seen from Fig. 2(a), the LPS profile of the P. baemolytica serotype A1 strain (PH468) lacked the well-defined ladder pattern seen in all but one of the $P$. trebalosi isolates and the same was true of other $P$. baemolytica isolates (profiles not shown). In addition, the core-oligosaccharide region of the A1 LPS of $P$. baemolytica possessed four bands whereas that of $P$. trebalosi possessed only one or two bands, although the resolution of the four bands was poor due to overstaining in order to demonstrate the O-chains of the A1 LPS (see also Davies et al., 1991, for further details). The LPS profiles of the $P$. trebalosi isolates could be differentiated into six 'smooth' LPS types, designated LPS types 1-6 and, as already mentioned, a single isolate, PH604, of serotype T3, did not possess a ladder pattern and was classified as 'rough' (Fig. 2a, lane 2).

Differentiation of the LPS into distinct types was based (1) on variation in the fastest-migrating low-molecular-mass bands representing the core-oligosaccharide region and 


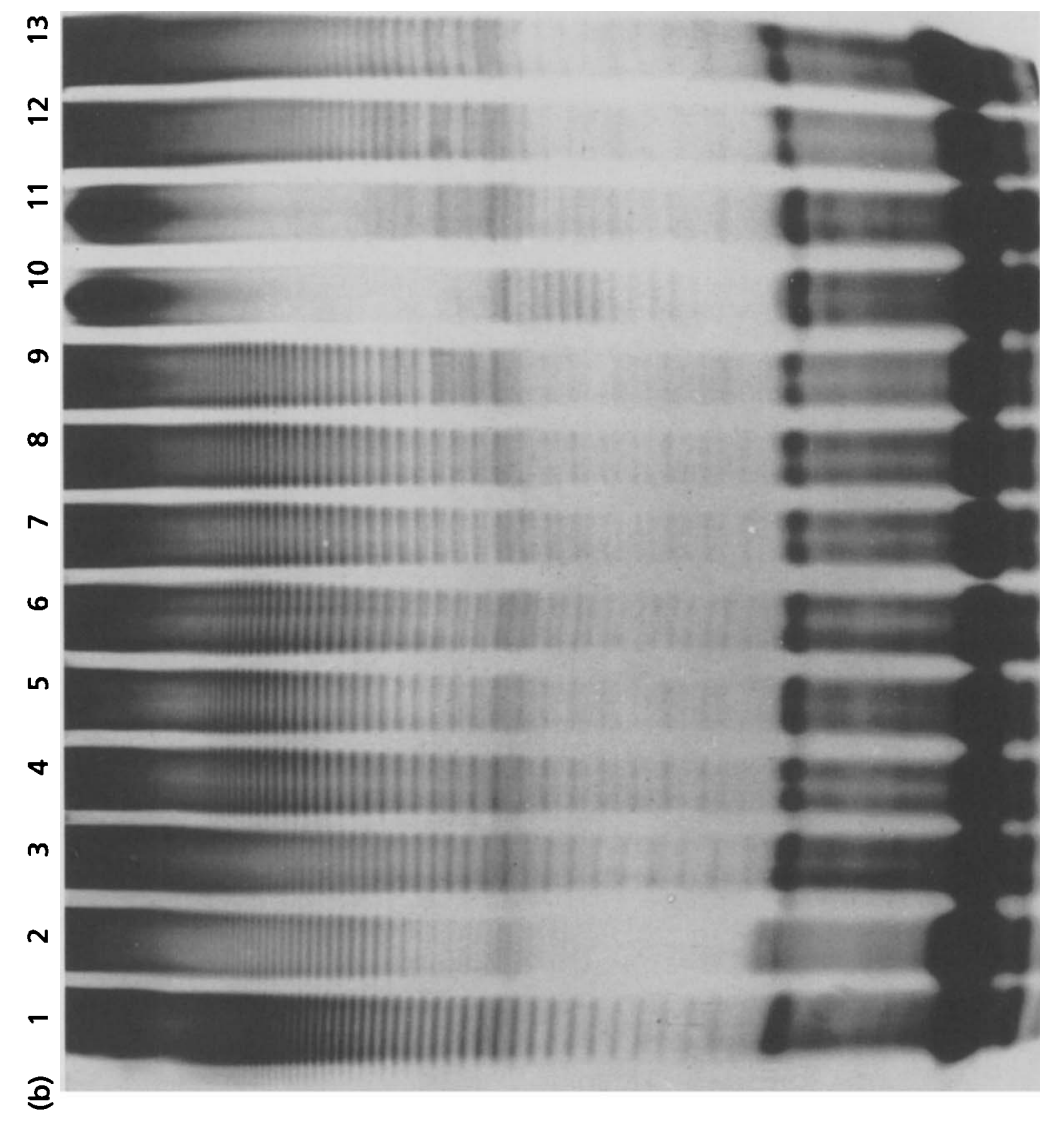

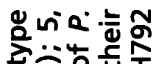

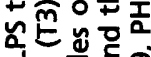

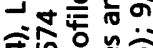

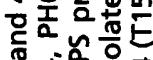

m。․․․

商全点㐱

$=\infty$

동둥

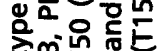

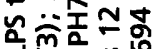

E

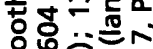

톤즌

DN

1

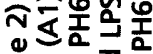

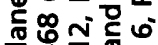

的立前会

으를

드으웡

은 충조은

도은

年远

可

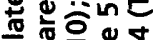

Oํㅡㄹ

पับ

중

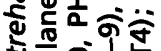

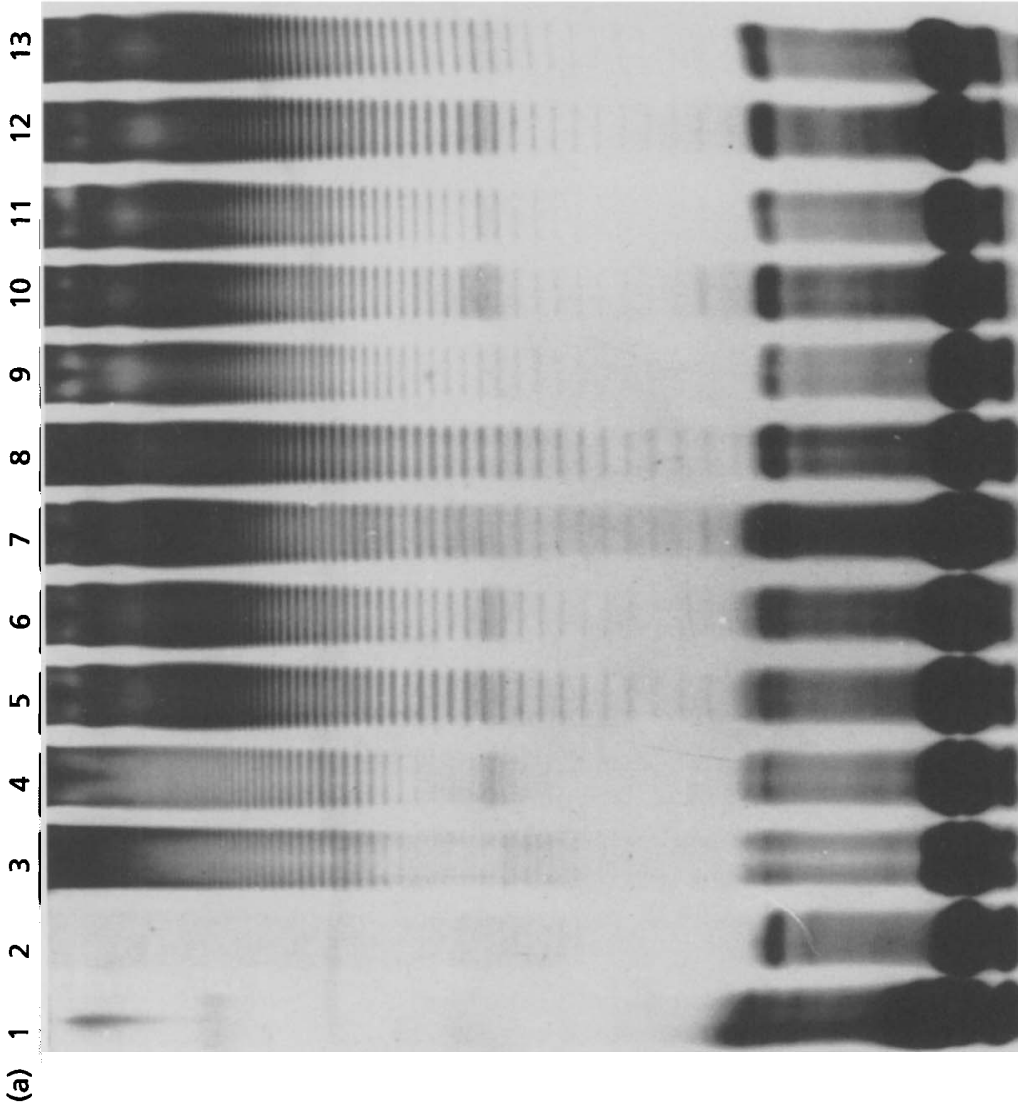

$0 . \equiv$ 응

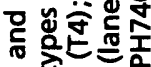

$=0 m_{m}$

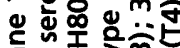

든

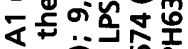

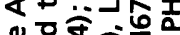

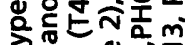

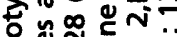

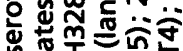

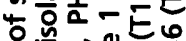
$0 \infty 00$

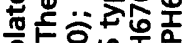
前记会重 ฐर ํํ오ำ ह

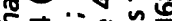

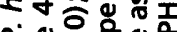

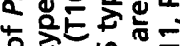
-

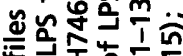
잉종현

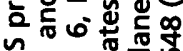

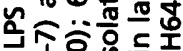
两的是:

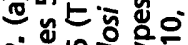
9 
(2) on variation in the appearance of the ladder pattern representing the O-antigen region. LPS types 1 and 2 were characterized by possessing two bands in the coreoligosaccharide region (Fig. 2a, lanes 3-7 and Fig. 2b, lane 2 ); by contrast, all other LPS types had a single band in this region. Unfortunately, optimum resolution of the individual bands has been partially lost during the photographic process. LPS types 1 and 2 could be differentiated on the basis that the individual bands within the ladders of LPS types 1 (Fig. 2a, lanes 3 and 4 ) and 2 (Fig. 2a, lanes 5-7), respectively, were in alignment with each other but were not in alignment with the bands of the other LPS type. This is best observed by placing a ruler across Fig. 2(a) and comparing the relative positions of bands in the LPS in lanes 3-7. The differences in molecular masses of individual bands within the ladders of LPS types 1 and 2 indicated different structures of the Oantigen repeat units. In addition, the ladder pattern of LPS type 1 consistently stained less intensely in the upper region of the gel than that of LPS type 2 . This is best seen by comparing lanes 4 and 5 in Fig. 2(a). Of the 60 isolates of $P$. trebalosi examined, only two possessed LPS type 1 and both of these were of serotype T3 (Table 1). Sixteen of the 60 isolates possessed LPS type 2 and all of these were of serotype T10 (Table 1).

LPS types 3 and 4 could be differentiated from LPS types 1 and 2 in having a single band in the low-molecular-mass core-oligosaccharide region (Fig. 2a, lanes 8-13; Fig. 2b, lanes 3-9). LPS type 3 could be differentiated from LPS type 4 in the same way that LPS types 1 and 2 could be differentiated. That is, the spacing of the individual bands in LPS types 3 and 4 differed and the ladder pattern of LPS type 3 stained less intensely in the upper region of the gel than that of LPS type 4. The ladder pattern of LPS type 4 had the same appearance, in terms of both spacing of the bands and intensity of staining, as that of LPS type 2 (Fig. 2a, compare lanes 5-7 with lanes 8-13). The ladder pattern of LPS type 3 was characterized by some of the bands having the appearance of doublets; there was also some micro-heterogeneity of the patterns assigned to this group. The doublet effect was more evident in the LPS of some isolates than others and is quite clearly seen in the LPS of isolates PH688 and PH694 in Fig. 2(b) (lanes 6 and 7). The ladder patterns of LPS types 1 and 3 were also very similar, even to the extent of clearly visible doublet bands in isolate PH68 (Fig. 2a, lane 3), although the absence of short chain LPS in the type 1 ladder patterns meant that the two profiles were not identical. Of the 60 isolates of $P$. trehalosi, 25 possessed LPS type 3 and 11 possessed LPS type 4 (Table 1). LPS type 3 was associated with isolates of serotypes T4, T15 and the UT isolates; LPS type 4 was associated with isolates of serotypes T4, T10 and T15.

The remaining LPS types, 5 and 6 , were not common and were associated with two isolates of serotype T15 and three isolates of serotype $\mathrm{T} 4$, respectively (Table 1 ). Both LPS types had ladder patterns which were dissimilar to any of the others (Fig. 2b, lanes 10-13), although LPS type 5 also had a low-molecular-mass band which was expressed more abundantly than in any of the other LPS types (Fig. 2b, lanes 10 and 11 ).

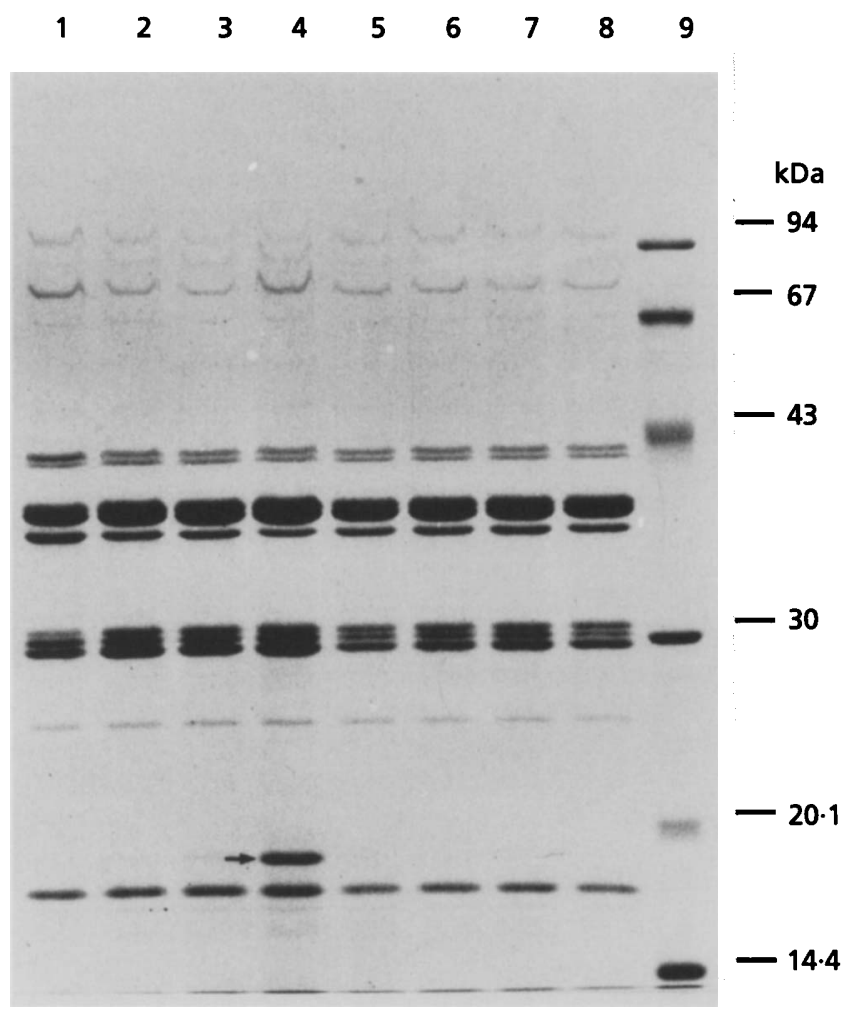

Fig. 3. OMP profiles of $P$. trehalosi isolate PH328 (serotype T4) after 4, 8, 12 and $24 \mathrm{~h}$ of growth in BHIB (lanes 1-4, respectively) and after 5, 10, 15 and 20 subcultures on sheep's blood agar (lanes 5-8, respectively).

\section{SDS-PAGE analysis of OMPs}

To determine whether any variation in OMP profiles occurred at different stages of the growth cycle or after repeated subculture, the OMP profiles of isolate $\mathrm{PH} 328$ were compared after 4, 8, 12 and $24 \mathrm{~h}$ of growth and after 5, 10, 15 and 20 subcultures. As can be seen from Fig. 3 (lanes 1-3) the OMP profiles of cells grown for 4, 8 and $12 \mathrm{~h}$ were identical. However, after $24 \mathrm{~h}$ of growth an additional protein of approximate molecular mass $19 \mathrm{kDa}$ was expressed (Fig. 3, lane 4, arrow). There was no change in the OMP profiles of isolate PH328 after repeated subculture (Fig. 3, lanes 5-8).

The OMP profiles of the 60 isolates of $P$. trebalosi were compared to each other and to the profiles of serotype A1 and A2 isolates of P. baemolytica (Fig. 4). Based on the above results, outer membranes of all the isolates were prepared from cells grown for approximately $6 \mathrm{~h}$, i.e. to late exponential phase. As can be seen from Fig. 4(a), the OMP profiles of $P$. haemolytica (lanes 1 and 2 ) and $P$. trebalosi (lanes 3-12) were very different. Important differences between $P$. baemolytica and $P$. trebalosi were apparent in the mobilities of major proteins in the molecular mass range $29-43 \mathrm{kDa}$ (Fig. 4a, lane 3 , arrows). In addition, a $17 \mathrm{kDa}$ protein was present in both serotypes of $P$. baemolytica but not in $P$. trehalosi (Fig. 4a, lane 2, arrow). Finally, differences between $P$. baemolytica and $P$. trebalosi were also apparent in the high-molecular- 
$\begin{array}{lllllllllllll}\text { (a) } 1 & 2 & 3 & 4 & 5 & 6 & 7 & 8 & 9 & 10 & 11 & 12 & 13\end{array}$

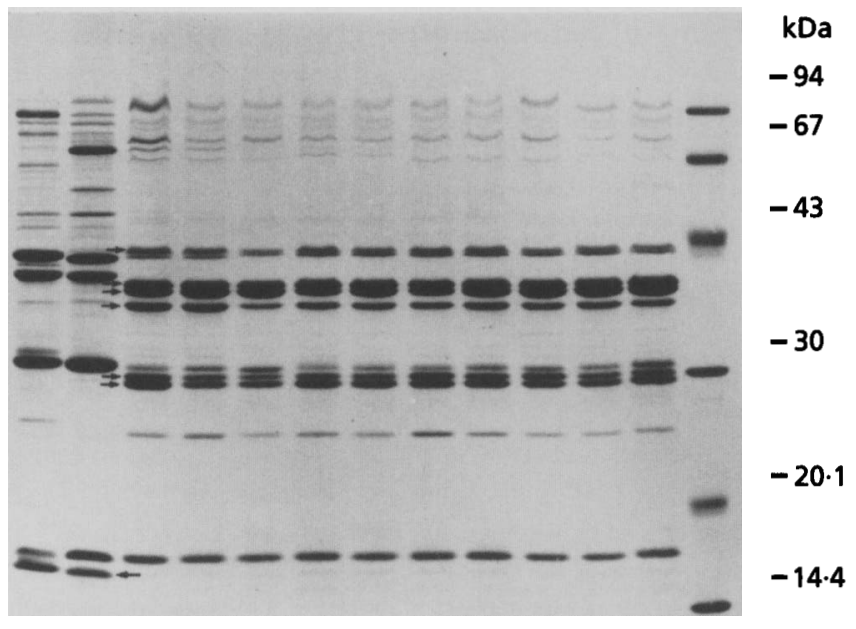

$\begin{array}{lllllllllllll}\text { (b) } 1 & 2 & 3 & 4 & 5 & 6 & 7 & 8 & 9 & 10 & 11 & 12 & 13\end{array}$

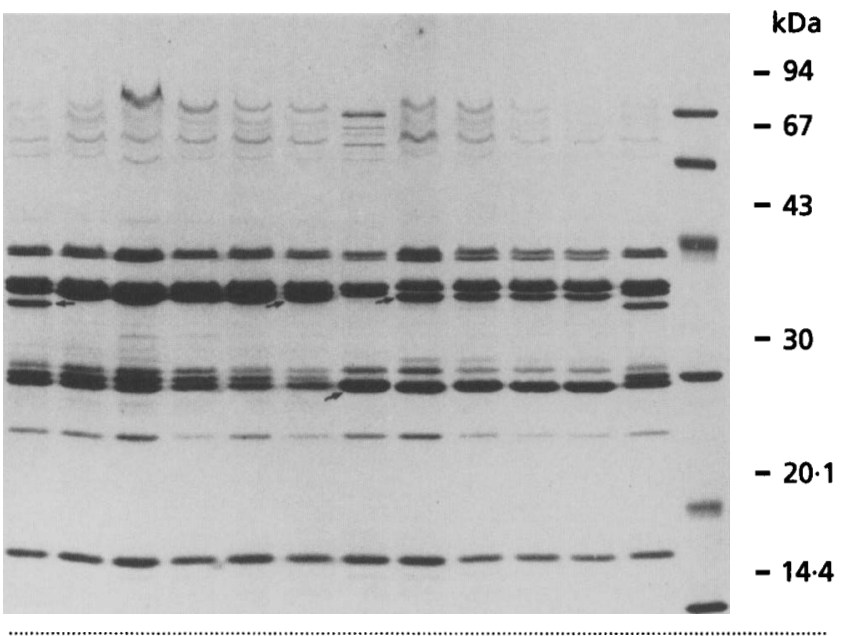

Fig. 4. (a) OMP profiles of $P$. haemolytica isolates of serotypes $A 1$ and A2 (lanes 1 and 2) and $P$. trehalosi isolates of serotypes T3, T4, T10 and T15 and OMP type 1 (lanes 3-12). The isolates and their serotypes in lanes 1-12 are as follows: 1, PH468 (A1); 2, PH776 (A2); 3, PH68 (T3); 4, PH674 (T3); 5, PH716 (T4); 6, PH728 (T4); 7, PH738 (T4); 8, PH724 (T10); 9, PH650 (T10); 10, PH764 (T10); 11, PH710 (T15); 12, PH752 (T15). Arrows (lane 3) indicate differences in mobilities of major proteins between $P$. haemolytica serotype $A 1$ and $A 2$ isolates and $P$. trehalosi isolates (see text for details). (b) OMP profiles of $P$. trehalosi isolates of OMP type 1 (lanes 1 and 12), OMP type 2 (lanes 2-6), OMP type 3 (lanes 8-11) and OMP type 4 (lane 7). The isolates and their serotypes in lanes 1-12 are as follows: 1, PH728 (T4); 2, PH734 (T4); 3, PH252 (T10); 4, PH780 (T15); 5, PH694 (T15); 6, PH696 (T15); 7, PH604 (T3); 8, PH70 (T15); 9, PH744 (T15); 10, PH792 (UT); 11, PH794 (UT); PH728 (T4). Arrows indicate differences in mobilities of major proteins between OMP types $1,2,3$ and 4 (see text for details).

mass region $67-100 \mathrm{kDa}$ (Fig. $4 \mathrm{a}$ ). However, the resolution of proteins in the high-molecular-mass region of all the $P$. trebalosi isolates was poor compared to that in the same region of the $P$. baemolytica isolates.

Within P. trehalosi itself, four distinct OMP profiles were evident and these were designated OMP types 1-4. OMP type 1 was the most common OMP profile and was present in isolates belonging to each of the four recognized serotypes as can be seen from Fig. 4(a) (lanes 3-12), which shows the OMP profiles of representative isolates of each of the four serotypes. In total, $45(75 \%)$ of the 60 isolates of $P$. trebalosi possessed OMP profiles of type 1 (Table 1). OMP type 2 was present in seven isolates, including isolates of serotypes T4, T10 and T15, and is shown in Fig. 4(b) (lanes 2-6). OMP type 2 differed from OMP type 1 in that the $35.5 \mathrm{kDa}$ protein of OMP type 1 (Fig. $4 \mathrm{~b}$, lane 1, arrow) appeared to have shifted in mobility to an apparent molecular mass of approximately $37 \mathrm{kDa}$ (Fig. 4b, lane 6, arrow), with the result that there now appeared to be three proteins in the range $37-39 \mathrm{kDa}$. This resulted in poor resolution of the proteins in this range (Fig. 4b, lanes 2-6). OMP type 3 was present in seven isolates and is shown in Fig. 4(b) (lanes 8-11). Isolates possessing OMP type 3 were restricted to serotype T15 and to the UT isolates, although three of the T15 isolates were cultures obtained from the NCTC and were at least 25 years old. In the OMP type 3 profile the $29 \mathrm{kDa}$ protein was expressed more abundantly than in OMP types 1 and 2 (Fig. 4b, lane 7, arrow) and the $30 \mathrm{kDa}$ protein appeared not to be expressed. Also, the $35.5 \mathrm{kDa}$ protein of OMP type 1 appeared to have shifted in mobility to an apparent molecular mass of $37 \mathrm{kDa}$, as in OMP type 2 (Fig. 4b, lane 8 , arrow), but there appeared to be only a single protein, of $39 \mathrm{kDa}$, above the $37 \mathrm{kDa}$ protein (compare Fig. 4b, lanes 11 and 12). OMP type 4 was present in only a single isolate, PH604 (Fig. 4b, lane 7). OMP type 4 was characterized by having two major proteins in the molecular mass range $37.5-38.5 \mathrm{kDa}$, but in the $29-31 \mathrm{kDa}$ range was identical to OMP type 3.

\section{DISCUSSION}

Since phenotypic characters such as LPS and OMPs are influenced by growth conditions and can change after subculture, the stability of the LPS and OMP profiles of $P$. trebalosi under different growth conditions was assessed at the outset. In particular, phase of growth, degree of aeration and iron-limitation have previously been shown to influence the OMP profiles of $P$. baemolytica (Davies $e t$ al., 1992). In the present study bacteria were grown under iron-sufficient conditions and the degree of aeration was maintained constant. The effects of phase of growth and subculture on the LPS and OMP profiles of a serotype T4 isolate were assessed. The LPS profiles were found to be the same both after repeated subculture and at different stages of the growth cycle. Although the OMP profiles of the same isolate did not change after repeated subculture, there was variation at different stages of growth. The OMP profiles of bacteria grown for 4-12 h were identical but an additional protein of $19 \mathrm{kDa}$ was expressed after $24 \mathrm{~h}$. In subsequent experiments bacteria were grown for approximately $6 \mathrm{~h}$ to minimize any effects due to cells entering stationary phase. Since there were no changes in either the LPS or OMP profiles after 20 subcultures it was concluded that the number of times an isolate had been subcultured before arriving in the laboratory was not important. 
Table 2. Summary of subdivision of $P$. haemolytica based on capsular serotypes, LPS types and OMP types

\begin{tabular}{|lccc|}
\hline Serotype & $\begin{array}{c}\text { LPS } \\
\text { type }\end{array}$ & $\begin{array}{c}\text { OMP } \\
\text { type }\end{array}$ & $\begin{array}{c}\text { No. of } \\
\text { isolates }\end{array}$ \\
\hline T3 & R & 4 & 1 \\
T3 & 1 & 1 & 2 \\
T4 & 3 & 1 & $8^{*}$ \\
T4 & 3 & 2 & $3 *$ \\
T4 & 4 & 1 & 4 \\
T4 & 6 & 1 & 3 \\
T10 & 2 & 1 & $16^{*}$ \\
T10 & 4 & 1 & 2 \\
T15 & 3 & 1 & 4 \\
T15 & 3 & 2 & 3 \\
T15 & 3 & 3 & $4 *$ \\
T15 & 4 & 1 & 5 \\
T15 & 5 & 1 & 2 \\
UT & 3 & 3 & $3^{*}$ \\
\hline
\end{tabular}

* Three isolates within each group derived from same host animal.

Significant differences between the OMP profiles of $P$. baemolytica and $P$. trebalosi confirmed the findings of other investigators which suggest that biotypes $A$ and $T$ of $P$. baemolytica are, in fact, different species (Sneath \& Stevens, 1985, 1990; Dewhirst et al., 1992). The high degree of variation in the molecular masses of the major proteins, in particular, indicated significant taxonomic differences between $P$. baemolytica and $P$. trehalosi, supporting the suggestion of Dewhirst et al. (1992) that the two species belong in different genera. By contrast, there was a low degree of intra-specific variation between the profiles of serotype A1 and A2 isolates of $P$. baemolytica (see also McCluskey et al., 1994) and between those of the $P$. trehalosi serotypes. Although there were differences in the nature of the $\mathrm{O}$-antigen side-chains of $P$. baemolytica (Davies et al., 1991) and P.trehalosi, further immunological characterization of the LPS of the two species, particularly of the core-oligosaccharide region, is required to demonstrate species-specific variation. Nevertheless, the welldefined ladder pattern present in all but one of the $P$. trebalosi isolates contrasted with the absence of a ladder pattern in serotype A2 isolates and the faint highmolecular-mass ladder pattern in serotype A1 isolates of P. baemolytica (Davies et al., 1991).

None of the three methods employed to assess diversity within $P$. trehalosi-variation in the capsular polysaccharides, and LPS and OMP profiles - was particularly discriminating when used alone because the degree of heterogeneity in each group of surface structures was limited. Only four capsular types, six smooth LPS types and four OMP types were identified within the population of 60 isolates examined. OMP typing was less useful than the other methods because $45(75 \%)$ of the isolates possessed the same OMP type, i.e. type 1, seven isolates possessed OMP types 2 or 3 , respectively, and a single isolate possessed OMP type 4. Overall, LPS typing was perhaps more useful than capsular serotyping, since six groups rather than four could be distinguished. However, there were differences in the association of the various LPS types with each of the capsular serotypes T4, T10 and T15 (Table 2). For example, LPS type 2 was associated only with serotype T10, LPS type 3 was associated with serotypes T4 and T15, and LPS type 4 was associated with each of the serotypes T4, T10 and T15. It should be noted that within serotype T10, LPS types 2 and 4 appear to have identical O-antigen types and differ only in the number of bands in the core-oligosaccharide region. Previous studies have shown that the O-antigen structures of 'T4' and 'T10' LPS (Perry \& Babiuk, 1984; Richards \& Leitch, 1989) and 'T3' and 'T15' LPS (Leitch \& Richards, 1988; Lacroix et al., 1993) are identical. However, these authors assumed that the LPS structures of the isolates chosen were representative of the T3, T4, T10 and T15 capsular groups, respectively. From the results presented here, this is clearly not the case, since LPS structure varies within capsular serotypes. Based on the observations described here, it seems likely that Perry \& Babiuk (1984) and Richards \& Leitch (1989) analysed the O-antigens of LPS types 2 (T10) and/or 4 (T4/T10), respectively, and Leitch \& Richards (1988) and Lacroix et al. (1993) analysed the O-antigens of LPS types 1 (T3) and 3 (T15), respectively. If this is the case, these structural studies support the observations of the present study regarding the relationship of LPS types 2 and 4 , and 1 and 3 although, as mentioned above, immunological analyses are required to confirm this.

When the three methods were used in combination, 14 distinct subgroups were delineated within the four serotypes as follows: $\mathrm{T} 3$ isolates, 2 subgroups; $\mathrm{T} 4$ isolates, 4 subgroups; T10 isolates, 2 subgroups; T15 isolates, 5 subgroups; UT isolates, 1 subgroup (summarized in Table 2). These subgroupings were clearly able to differentiate isolates of the same serotype and from the same VI Centre. For example, isolates of serotype T4 from Penrith VI Centre could be separated into three subgroups: LPS type 3/OMP type 1; LPS type 3/OMP type 2 ; and LPS type 4/OMP type 1 . Some subgroups were restricted to one serotype only, namely LPS/OMP types $\mathrm{R} / 4,1 / 1,6 / 1,2 / 1$ and $5 / 1$. Other subgroups were found in up to three serotypes, e.g. types $3 / 1$ and $3 / 2$ among both serotype T4 and T15 isolates, type $3 / 3$ within serotype T15 and the UT group, and type 4/1 within the three serotypes $\mathrm{T} 4, \mathrm{~T} 10$ and $\mathrm{T} 15$. The relative homogeneity of the OMP profiles was a possible indication of limited genetic diversity within the species. The T10 group of isolates, which comprised isolates possessing LPS types 2 and 4, and OMP profiles only of type 1, was clearly more homogeneous than the T4 and T15 groups, each of which possessed a wider range of LPS and OMP profiles. The frequent occurrence of serotype T10 isolates of LPS/OMP type $2 / 1$, originating from diverse geographical areas (samples within this group were obtained from seven different VI Centres in England, Scotland and Wales), marked the existence of an important clonal group within $P$. trebalosi which was responsible for a high 
proportion $(31 \%)$ of the recent disease outbreaks. LPS and OMP types, used in combination, are useful markers for the identification of clonal groups (Achtman \& Pluschke, 1986; Kapur et al., 1992). In addition, the occurrence of LPS/OMP type $3 / 3$ in both recent field isolates and NCTC cultures isolated 25-35 years ago marked the existence of a clonal group which has remained relatively unchanged for over 35 years. However, the fact that three of the field isolates belonging to this clone were untypable suggests either that the capsular structure of these isolates has changed or that this capsular type has remained unrecognized over this period of time.

The fact that the population was not dominated by a single capsular serotype suggests that, with the exception of the T3 capsule (see below), there were no significant differences in the virulence potential of the various capsular polysaccharides. That the T4 and T15 capsules do not vary significantly in their potential as virulence determinants is supported by the fact that the chemical structures of these capsular polysaccharides are almost identical (Adlam et al., 1985a, b). The similarity of the T4 and T15 capsules, together with the existence of isolates of each serotype having the same LPS/OMP profiles, namely $3 / 1,3 / 2$ and $4 / 1$, suggests that a high proportion of 'T4 and T15 isolates are closely related. Conversely, T10 isolates of LPS/OMP type $2 / 1$ are probably less closely related to the T4 and T15 isolates. The high incidence of the T10 clone possessing LPS/OMP type 2/1, and its recovery from diverse geographical locations within the UK, suggests that the T10/LPS type 2/OMP type 1 combination might be an important virulence determinant. Of these surface structures it is likely that the type 2 LPS is the most important since OMP profiles of type 1 are commonly associated with other serotypes and LPS types, and the T10 capsule is no more common than the T4 or T15 capsules, as mentioned above. Similarly, the low incidence of serotype $\mathrm{T} 3$ isolates from disease cases, which agrees with previous observations (Gilmour \& Gilmour, 1989), suggests that this serotype is possibly less virulent than the other serotypes. Although these conclusions are speculative they are, nevertheless, concordant with observations in other clonal populations, where a small number of virulent clones are responsible for a majority of the disease outbreaks (Selander \& Musser, 1990). Based on the incidence of these surface components among the disease isolates examined, the study has highlighted important areas for future research regarding the role of specific surface components in disease. In particular, the immunological relationships of the different LPS types to each other, and the role of the different capsular and LPS structures in virulence, need to be assessed experimentally.

In summary, our analysis of variation of the capsular polysaccharide serotypes, and LPS and OMP profiles, has shown that by comparison to other species, $P$. trebalosi is relatively homogeneous: only four capsular serotypes, six LPS types and four OMP types were identified in a geographically diverse sample of isolates. However, when the three typing methods were employed together, they were demonstrated to be very effective as an epidemio- logical tool, and capable of identifying important clonal groups and specific surface components likely to be involved in virulence. The underlying genetic diversity of $P$. trehalosi is currently being investigated by multilocus enzyme electophoresis.

\section{ACKNOWLEDGEMENTS}

This study was supported by a Wellcome Fellowship to R. L. Davies (Ref. 038464/Z/93/Z/REH/MW). The study would not have been possible without the help and cooperation of staff at various Veterinary Investigation Centres in the UK. For this particular study we are grateful to staff at the following VI Centres: Aberdeen, Auchincruvie, Dumfries, Edinburgh and St Boswells (Scotland), Shrewsbury and Penrith (England), and Aberystwyth and Carmarthen (Wales). We are particularly grateful to Dr David Dyson (Penrith) and Dr Chris Low (Edinburgh) for their interest, advice and help. We are also grateful to Norman Tait for the photographic work.

\section{REFERENCES}

Abdullah, K. M., Lo, R. Y. C. \& Mellors, A. (1990). Distribution of glycoprotease activity and the glycoprotease gene among serotypes of Pasteurella baemolytica. Biochem Soc Trans 18, 901-903.

Achtman, M. \& Pluschke, G. (1986). Clonal analysis of descent and virulence among selected Escherichia coli. Annu Rev Microbiol 40, 185-210.

Adlam, C. (1989). The structure, function and properties of cellular and extracellular components of Pasteurella baemolytica. In Pasteurella and Pasteurellosis, pp. 75-92. Edited by C. F. Adlam \& J. M. Rutter. London: Academic Press.

Adlam, C., Knights, J. M., Mugridge, A., Lindon, J. C. \& Williams, J. M. (1985a). Purification, characterization, and immunological properties of the serotype-specific capsular polysaccharide of Pasteurella baemolytica (serotype T4) organisms. J Gen Microbiol 131, 387-394.

Adlam, C., Knights, J. M., Mugridge, A., Lindon, J. C., Williams, J. M. \& Beesley, J. E. (1985b). Purification, characterization, and immunological properties of the capsular polysaccharide of Pasteurella baemolytica serotype T15: its identity with the K62 (K2ab) capsular polysaccharide of Escherichia coli and the capsular polysaccharide of Neisseria meningitidis serogroup H. J Gen Microbiol 131, 1963-1972.

Davies, R. L., Ali, Q., Parton, R., Coote, J. G., Gibbs, H. A. \& Freer, J.H. (1991). Optimal conditions for the analysis of Pasteurella baemolytica lipopolysaccharide by sodium dodecyl sulphate-polyacrylamide gel electrophoresis. FEMS Microbiol Lett 90, 23-28.

Davies, R. L., Parton, R., Coote, J. G., Gibbs, H. A. \& Freer, J. H. (1992). Outer membrane protein and lipopolysaccharide variation in Pasteurella baemolytica A1 under different growth conditions. $J$ Gen Microbiol 138, 909-922.

Dewhirst, F. E., Paster, B. J., Olsen, I. \& Fraser, G. J. (1992). Phylogeny of 54 representative strains of species in the family Pasteurellaceae as determined by comparison of $16 \mathrm{~S}$ rRNA sequences. J Bacteriol 174, 2002-2013.

Filip, C., Fletcher, G., Wulff, J. L. \& Earhart, C. F. (1973). Solubilization of the cytoplasmic membrane of Escherichia coli by the ionic detergent sodium-lauryl sarcosinate. J Bacteriol 115, 717-722.

Fraser, J. \& Donachie, W. (1983). Rapid indirect haemagglutination test for serotyping Pasteurella baemolytica. J Clin Microbiol 18, 206-207.

Gerbig, D. G., Cameron, M. R., Struck, D. K. \& Moore, R. N. (1992). 
Characterization of a neutralizing monoclonal antibody to Pasteurella baemolytica leukotoxin. Infect Immun 60, 1734-1739.

Gilmour, N. J. L. \& Gilmour, J. S. (1989). Pasteurellosis of sheep. In Pasteurella and Pasteurellosis, pp. 223-261. Edited by C. F. Adlam \& J. M Rutter. London: Academic Press.

Hitchcock, P. J. \& Brown, T. M. (1983). Morphological heterogeneity among Salmonella lipopolysaccharide chemotypes in silverstained polyacrylamide gels. $J$ Bacteriol 154, 269-277.

Jaworski, M. D., Ward, A. C. S., Hunter, D. L. \& Wesley, I. V. (1993). Use of DNA analysis of Pasteurella baemolytica biotype T isolates to monotor transmission in bighorn sheep (Ovis canadensis canadensis). J Clin Microbiol 31, 831-835.

Kapur, V., White, D. G. , Wilson, R. A. \& Whittam, T. S. (1992). Outer membrane protein patterns mark clones of Escbericbia coli $\mathrm{O} 2$ and O78 strains that cause avian septicemia. Infect Immun 60, 1687-1691.

Knights, J. M., Adlam, C. \& Owen, P. (1990). Characterization of envelope proteins from Pasteurella baemolytica and Pasteurella multocida. J Gen Microbiol 136, 495-505.

Lacroix, R. P., Duncan, J. R., Jenkins, R. P., Leitch, R. A., Perry, J. A. \& Richards, J. C. (1993). Structural and serological specificities of Pasteurella baemolytica lipopolysaccharides. Infect Immun 61, 170-181.

Laemmli, U. K. (1970). Cleavage of structural proteins during the assembly of the head of bacteriophage T4. Nature 227, 680-685.

Lee, C. W., Lo, R. Y. C., Shewen, P. E. \& Mellors, A. (1994). The detection of the sialoglycoprotease gene and assay for sialoglycoprotease activity among isolates of Pasteurella baemolytica A1 strains, serotypes A13, A14, T15 and A16. FEMS Microbiol Lett 121, 199-206.

Leitch, R. A. \& Richards, J. C. (1988). Structure of the O-chain of the lipopolysaccharide of Pasteurella baemolytica serotype T3. Biochem Cell Biol 66, 1055-1065.

McCluskey, J., Gibbs , H. A. \& Davies, R. L. (1994). Variation in outer-membrane protein and lipopolysaccharide profiles of
Pasteurella baemolytica isolates of serotypes A1 and A2 obtained from pneumonic and healthy cattle. Microbiology 140, 807-814.

Markwell, M. A. K., Haas, S. M., Bieber, L. L. \& Tolbert, N. E. (1978). A modification of the Lowry procedure to simplify protein determination in membrane and lipoprotein samples. Anal Biochem 87, 206-210.

Mutters, R., Mannheim, W. \& Bisgaard, M. (1989). Taxonomy of the group. In Pasteurella and Pasteurellosis, pp. 3-34. Edited by C. F. Adlam \& J. M Rutter. London: Academic Press.

Perry, M. B. \& Babiuk, L. A. (1984). Structure of the polysaccharide chain of Pasteurella baemolytica (serotype 4) lipopolysaccharide. Can $J$ Biocbem Cell Biol 62, 108-114.

Richards, J. C. \& Leitch, R. A. (1989). Elucidation of the stucture of the Pasteurella baemolytica serotype T10 lipopolysaccharide Oantigen by NMR spectroscopy. Carbobydr Res 186, 275-286.

Selander, R. K. \& Musser, J. M. (1990). Population genetics of bacterial pathogenesis. In The Bacteria, pp. 11-36. Edited by B. H. Iglewski \& V. L. Clark. London: Academic Press.

Sneath, P. H. A. \& Stevens, M. (1985). A numerical taxonomic study of Actinobacillus, Pasteurella and Yersinia. J Gen Microbiol 131, 2711-2738.

Sneath, P. H. A. \& Stevens, M. (1990). Actinobacillus rossii sp. nov., Actinobacillus seminis sp. nov., nom. rev., Pasteurella bettii sp. nov., Pasteurella lymphangitidis sp. nov., Pasteurella mairi sp. nov., and Pasteurella trebalosi sp. nov. Int J Syst Bacteriol 40, 148-153.

Tsai, C. M. \& Frasch, C. E. (1982). A sensitive silver stain for detecting lipopolysaccharide in polyacrylamide gels. Anal Biochem 119, 115-119.

Younan, M. \& Fodor, L. (1995). Characterisation of a new Pasteurella baemolytica serotype (A17). Res Vet Sci 58, 98.

Received 23 August 1995; revised 26 October 1995; accepted 3 November 1995. 